\title{
PERAN KELEMBAGAAN GABUNGAN KELOMPOK TANI DALAM PENGELOLAAN HUTAN KEMASYARAKATAN
}

\author{
The Institutional Role of Farmer Groups in Community Forest Management
}

\author{
Alifia Putri Larasati ${ }^{1^{\star}}$, Christine Wulandari ${ }^{1,2}$, Indra Gumay Febryano $^{1}$ dan Hari \\ Kaskoyo ${ }^{1}$ \\ 1Jurusan Kehutanan, Fakultas Pertanian, Universitas Lampung \\ ${ }^{2}$ Magister IImu Kehutanan, Universitas Lampung \\ JIn. Prof. Dr. Soemantri Brojonegoro No. 1 Gedung Meneng, Bandar Lampung \\ *Email : alifiaplarasati@gmail.com
}

Diterima : 20/01/2020, Direvisi : 11/05/2020, Diterbitkan 01/03/2021

\begin{abstract}
Gapoktan institutions has important roles, including its functions to regulate community activities, individually or in groups, on managing community forests. This study aims to explain the management of HKm based on the role of gapoktan institutions. The research methodology are interview and documentation study. The data obtained were analyzed descriptively. Results showed that institutionally Gapoktan has a complete administration and written rules regarding the management of $\mathrm{HKm}$. Each farmer member is required to work on land with agroforestry patterns dominated by MPTS plants. Gapoktan has a farming business that functions to help market forest products. Farming management is divided into two, namely individual businesses and gapoktan businesses. Until now there has been no significant development of farming in the last two years. Therefore, the government needs to conduct counseling to increase knowledge about farming so that they can market forest products more optimally.
\end{abstract}

Keywords; community forestry; gapoktan institutions; farming business.

\begin{abstract}
ABSTRAK
Kelembagaan gapoktan memiliki peran penting yang berfungsi mengatur aktivitas masyarakat secara individu ataupun kelompok dalam mengelola hutan kemasyarakatan. Penelitian ini bertujuan untuk menjelaskan pengelolaan $\mathrm{HKm}$ berdasarkan peran kelembagaan gapoktan. Metode yang digunakan yaitu wawancara dan studi dokumentasi. Data yang diperoleh dianalisis secara deskriptif. Hasil penelitian menunjukkan bahwa secara kelembagaan gapoktan memiliki administrasi yang lengkap dan aturan main secara tertulis terkait pengelolaan $\mathrm{HKm}$. Setiap anggota tani wajib menggarap lahan dengan pola agroforestri yang didominasi tanaman MPTS. Gapoktan memiliki usaha tani yang berfungsi membantu memasarkan hasil hutan. Kelola usaha tani dibagi menjadi dua, yaitu usaha individu dan usaha gapoktan. Sampai saat ini belum ada perkembangan usaha tani secara signifikan selama dua tahun terakhir. Oleh karena itu, pemerintah perlu mengadakan penyuluhan untuk meningkatkan pengetahuan tentang usaha tani agar mereka dapat memasarkan hasil hutan lebih optimal.
\end{abstract}

Kata kunci; hutan kemasyarakatan; kelembagaan gapoktan; usaha tani. 


\section{PENDAHULUAN}

Kehutanan masyarakat merupakan salah satu cara untuk mengelola hutan (Stoen, 2018; Vega, 2019). Pemanfaatan hutan diberikan sebagai insentif kepada masyarakat untuk dikelola agar dapat meminimalkan konflik penggunaan lahan (Kaskoyo et al., 2014). Pemanfaatan tersebut dapat berupa kegiatan konservasi dan pengelolaan hasil hutan (Baral, 2018; Perrson \& Prowse, 2017). Hasil hutan dikelola berdasarkan aturan dan mekanisme tata kelola yang berlaku (Caballero, 2014; Gibran et al., 2018).

Berdasarkan Peraturan Menteri Lingkungan Hidup dan Kehutanan Nomor P.83/MENLHK/SETJEN/KUM.1/10/2016 tentang Perhutanan Sosial bahwa Hutan Kemasyarakatan $(\mathrm{HKm})$ merupakan salah satu skema dari perhutanan sosial. Menurut Safe'i et al. (2018) HKm adalah program pemanfaatan sumberdaya hutan yang mengedepankan aspek keberlanjutan. Program HKm ditujukan untuk meningkatkan kesejahteraan masyarakat dengan memanfaatkan sumberdaya hutan secara optimal, adil, dan berkelanjutan (Kaskoyo et al., 2017). Salah satu pemegang izin kelola HKm adalah Gabungan Kelompok Tani (Gapoktan). Gapoktan memiliki mekanisme tata kelola lahan yang tertuang dalam bentuk kelembagaan.

Kelembagaan berperan penting dalam pengelolaan $\mathrm{HKm}$. Hal tersebut disebabkan karena kelembagaan mengatur pengelolaan sumberdaya agar tetap berkelanjutan (Porro et al., 2015; Febryano et al., 2014; Febryano et al., 2017). Adanya kelembagaan dapat menjadi dasar dalam melaksanakan program HKm karena saat ini masih ditemukannya kendala dan tantangan dalam pengelolaan (Lewis \& Davis, 2015; Safe'i et al., 2018). Aminah (2018) menjelaskan bahwa kelembagaan yang aktif akan cenderung memberikan dampak positif terhadap kedinamisan kelompok. Permasalahan penelitian yaitu bagaimana peran kelembagaan gapoktan dalam pengelolaan $\mathrm{HKm}$. Tujuan penelitian adalah untuk menjelaskan peran kelembagaan gapoktan dalam mengelola $\mathrm{HKm}$.

\section{METODE}

Penelitian dilakukan di Desa Gisting Atas, Kecamatan Gisting, Kabupaten Tanggamus (Gambar 1) dari bulan September hingga November 2019. Lokasi penelitian dipilih secara sengaja (purposive) karena dianggap sebagai gapoktan unggulan oleh KPH Pematang Neba dan pernah meraih juara pertama Lomba Wana Lestari tingkat nasional. Objek penelitian ini adalah pengurus kelompok tani Gapoktan Wira Karya Sejahtera. Alat yang digunakan dalam penelitian adalah kamera, laptop, dan kuesioner. Pengumpulan data dilakukan dengan cara wawancara dan studi dokumentasi. Data primer yang dibutuhkan berupa kelola kelembagaan, kelola kawasan dan kelola usaha tani. Data sekunder yang digunakan berupa Surat Keputusan (SK) Penataan Areal Kawasan HKm, Izin Usaha Pengelolaan Hutan Kemasyarakatan (IUPHKm), rencana umum, Anggaran Dasar dan Anggaran Rumah Tangga (AD/ART), serta aturan kelompok Gapoktan Wira Karya Sejahtera.

Jumlah sampel penelitian diambil menggunakan metode purposive sampling yang terdiri dari ketua gapoktan 1 orang, ketua kelompok tani hutan 20 orang dan ketua kelompok wanita tani 1 orang. Data penelitian diperoleh dan diolah berdasarkan acuan Peraturan Menteri Kehutanan Nomor P.57/Menhut-II/2014 tentang Pedoman Pembinaan Kelompok Tani Hutan melalui pemberian skor penilaian kuesioner terkait kemampuan KTH dengan ketentuan: a) di bawah 350: Kelas Pemula, b) 350-700: Kelas Madya dan c) di atas 700: Kelas Utama. Data tersebut selanjutnya dianalisis secara deskriptif. 


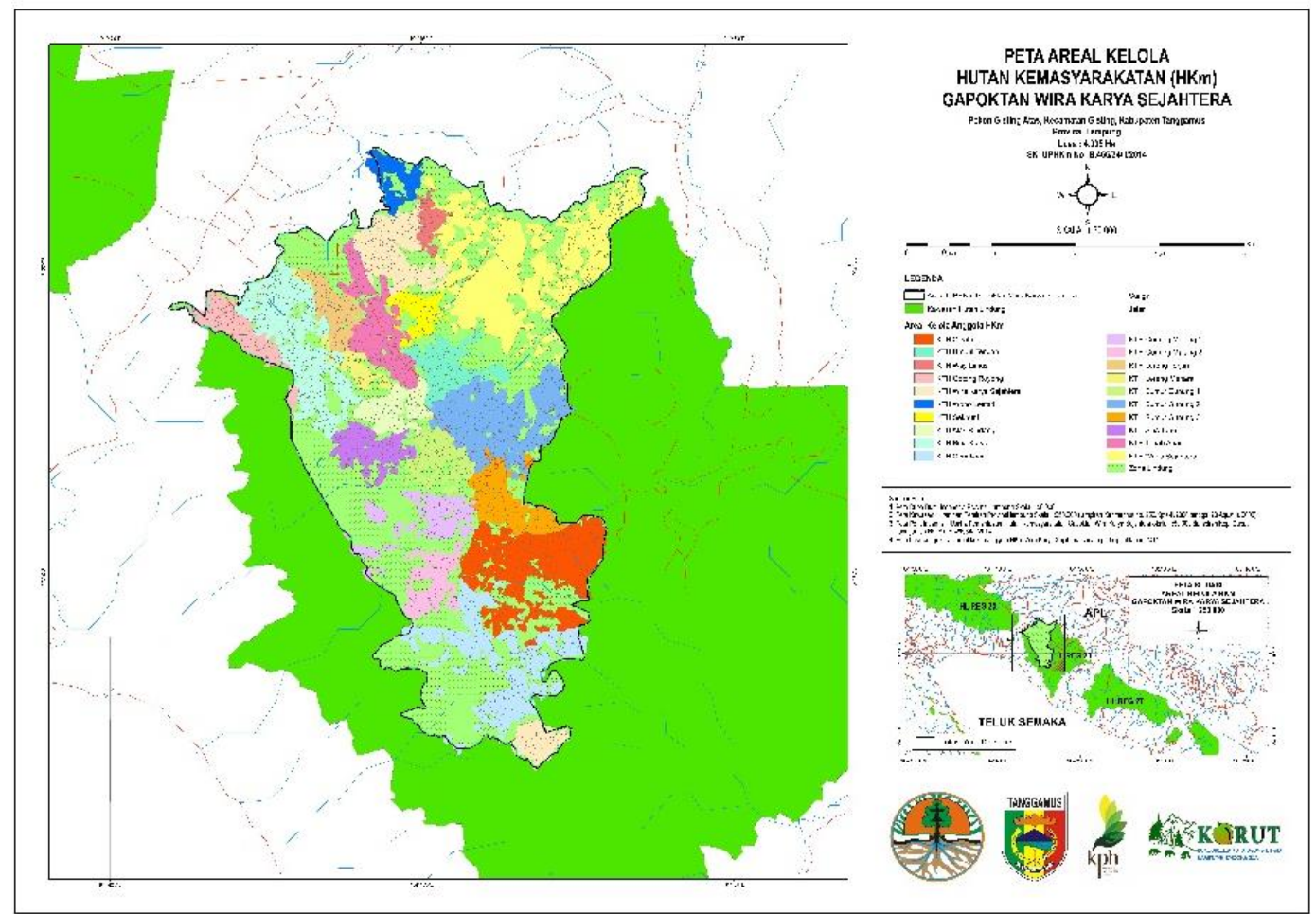

Gambar 1. Peta lokasi penelitian.

Figure 1. Map of research location.

\section{HASIL DAN PEMBAHASAN,}

\section{A. Kondisi Umum Lokasi}

Gapoktan Wira Karya Sejahtera berada di Dusun Way Tebu, Desa Gisting Atas, Kecamatan Gisting, Kabupaten Tanggamus. Gapoktan ini memiliki 2.055 anggota tani yang terbagi menjadi 20 Kelompok Tani Hutan (KTH) dan 1 Kelompok Wanita Tani (KWT), antara lain KTH Lereng Terjun (94 anggota), KTH Lereng Menara (34 anggota), KTH Alas Tabu (47 anggota), KTH Alas Rindang (50 anggota), KTH Sumur Gunung I (58 anggota), KTH Sumur Gunung II (130 anggota), KTH Sumur Gunung III (52 anggota), KTH Tanah Abang (154 anggota), KTH Gunung Malang I (66 anggota), KTH Gunung Malang II (44 anggota), KTH Umbul Tengah (71 anggota), KTH Cipatat (22 anggota), KTH Cengkaan (49 anggota), KWT Mawar Putih (26 anggota), KTH Way Limus (43 anggota), KTH Wono Lestari (38 anggota), KTH Wira Karya Sejahtera (367 anggota), KTH Sekhuni (25 anggota), KTH Wana Sejahtera (210 angsgota), KTH Bina Karya (253 anggota) dan KTH Gotong Royong (222 anggota).

Areal kerja gapoktan merupakan bagian dari Register $28 \mathrm{KPH}$ Pematang Neba yang terbagi dalam dua zona, yaitu zona pemanfaatan (budidaya) seluas 2.800 ha dan zona perlindungan (lindung) seluas 1.505 ha. Berdasarkan Rencana Umum Gapoktan Wira Karya Sejahtera tahun 2015, potensi areal kerja HKm terdiri atas tanaman tajuk tinggi, tanaman Multi Purpose Tree Species (MPTS), sumberdaya air, kebun percontohan (demplot), wisata alam dan fauna dilindungi.

Aturan main yang diterapkan gapoktan tertuang dalam Anggaran Dasar dan Anggaran Rumah Tangga (AD/ART), aturan kelompok, dan rencana umum. Kelompok tani yang tergabung dalam gapoktan ini memiliki dasar hukum berupa Surat Keputusan Menteri Kehutanan Republik Indonesia Nomor SK.887/Menhut-II/2013 tentang Penetapan Areal 
Kerja Hutan Kemasyarakatan pada kawasan hutan lindung di Kabupaten Tanggamus Provinsi Lampung dan SK Bupati Tanggamus Nomor B.466/34/II/2014 tentang IUPHKm atas nama Gapoktan Wira Karya Sejahtera Kecamatan Gisting Kabupaten Tanggamus yang saat ini telah diperbaharui dengan SK Menteri Lingkungan Hidup dan Kehutanan Republik Indonesia Nomor SK.6558/MENLHK-PSKL/PKPS/PSL.0/7/2019.

Gapoktan Wira Karya Sejahtera mengelola areal HKm seluas \pm 4.203 ha. Pola penanaman yang diterapkan semua kelompok tani adalah agroforestri. Agroforestri merupakan sistem penggunaan lahan yang dikombinasi pepohonan dan tanaman semusim (Salampessy et al., 2012; Rajagukguk et al., 2018; Nasichah et al., 2018). Pola penanaman ini sudah sesuai dengan Peraturan Direktur Jenderal Perhutanan Sosial dan Kemitraan Lingkungan Nomor P.16/PSKL/SET/PSL.0/12/2016 pada Pasal 7 Ayat 3 poin d yaitu: "pemanfaatan kawasan hutan meliputi budidaya tanaman obat, tanaman hias, jamur, lebah, penangkaran satwa liar atau budidaya hijauan makanan ternak, agroforestry, silvopasture dan silvofishery".

\section{B. Peran Kelembagaan Gapoktan Wira Karya Sejahtera}

Gapoktan Wira Karya Sejahtera memiliki 20 KTH dan 1 KWT (Tabel 1). Semua institusi termasuk dalam kelas madya. Kelas madya merupakan kelas dengan prioritas pembinaan pada aspek kawasan. Kelompok tani yang memperoleh nilai akhir tinggi adalah KTH Gotong Royong dan KTH Gunung Malang I. Kelompok yang memiliki nilai akhir rendah adalah KTH Way Limus dan KTH Alas Rindang. Nilai terendah pada kedua KTH tersebut berasal dari aspek kelola usaha. Hal ini disebabkan kurangnya perencanaan KTH dalam memanfaatkan dan memasarkan hasil hutan.

Berdasarkan Peraturan Menteri Kehutanan Nomor P.57/Menhut-II/2014 tentang Pedoman Pembinaan Kelompok Tani Hutan, kelembagaan menjelaskan pembagian tugas, peran, tanggungjawab dan wewenang masing-masing pengurus. Pada aspek kelembagaan, peraturan tersebut lebih menekankan pada struktur organisasi daripada aturan main itu sendiri. Penjelasan terkait kelembagaan sebagai aturan main dijelaskan pada aspek kelola kawasan dan kelola usaha. Menurut Schmid (2004), kelembagaan merupakan sejumlah peraturan yang berlaku dalam sebuah masyarakat, kelompok atau komunitas, yang mengatur hak, kewajiban, tanggung jawab, baik sebagai individu maupun sebagai kelompok.

Tabel 1. Penilaian peran kelembagaan gapoktan

Table 1. Rank of institutional role of gapoktan

\begin{tabular}{clcc}
\hline No. & \multicolumn{1}{c}{ Institusi } & Nilai Akhir & Tingkatan Kelas \\
\hline 1. & KTH Gotong Royong & 515 & Madya \\
2. & KTH Bina Karya & 450 & Madya \\
3. & KTH Gunung Malang I & 450 & Madya \\
4. & KTH Gunung Malang II & 515 & Madya \\
5. & KTH Lereng Menara & 460 & Madya \\
6. & KTH Tanah Abang & 455 & Madya \\
7. & KTH Alas Tabu & 485 & Madya \\
8. & KTH Sumur Gunung I & 490 & Madya \\
9. & KTH Sumur Gunung II & 460 & Madya \\
10. & KTH Sumur Gunung III & 495 & Madya \\
11. & KWT Mawar Putih & 500 & Madya \\
12. & KTH Cipatat & 465 & Madya \\
13. & KTH Umbul Tengah & 475 & Madya \\
14. & KTH Lereng Terjun & 455 & Madya \\
15. & KTH Cengkaan & 465 & Madya \\
16. & KTH Wono Lestari & 460 & Madya \\
17. & KTH Way Limus & 445 & Madya
\end{tabular}




\begin{tabular}{llll} 
18. & KTH WKS Purwodadi & 510 & Madya \\
19. & KTH Alas Rindang & 445 & Madya \\
20. & KTH Sekhuni & 500 & Madya \\
21. & KTH Wana Sejahtera & 500 & Madya \\
22. & Gapoktan Wira Karya Sejahtera & 670 & Madya \\
\hline \multicolumn{2}{c}{ Kumulatif } & 485 & Madya \\
\hline
\end{tabular}

Sumber: Data Primer (2019).

Kelembagaan gapoktan berperan dalam mengatur aktivitas pengelolaan dan pemanfaatan $\mathrm{HKm}$. Peran kelembagaan gapoktan dijelaskan sebagai berikut:

\section{Kelola Kelembagaan}

Gapoktan Wira Karya Sejahtera memiliki sistem kepengurusan yang terdiri dari ketua gapoktan, wakil ketua, sekretaris, bendahara dan seksi-seksi unit usaha yang dimiliki terkait pengelolaan HKm. Gapoktan ini telah memiliki rencana umum secara tertulis untuk mengatur kegiatan kelompok tani dengan tujuan untuk menciptakan pola kebersamaan dalam pengelolaan hutan yang berkesinambungan sesuai konsep kelembagaaan. Sejalan dengan Sya'rani et al. (2017) bahwa konsep kelembagaan menunjukkan hubungan pola tindakan yang membaur dalam organisasi dan bersifat normatif.

Pengurus KTH, gapoktan dan anggota tani terlibat dalam setiap pelaksanaan kegiatan kelompok sekitar 50-75\%. Hal ini sudah sesuai dengan aturan kelompok dan AD/ART Gapoktan Wira Karya Sejahtera pada Pasal 10 Ayat 4 yaitu: "rapat umum anggota dianggap sah, bila dihadiri setengah ditambah satu dari anggota yang diundang". Pemantauan dan evaluasi pengelolaan $\mathrm{HKm}$ dilakukan oleh pengurus pada masingmasing $\mathrm{KTH}$, namun tidak secara periodik. Hal ini karena tidak adanya jadwal pemantauan dan evaluasi secara tertulis. Penetapan lokasi dan kelengkapan serta pengaktifan fungsi sekretariat rata-rata memiliki 3-5 unsur, diantaranya papan nama $\mathrm{KTH}$, pondok pertemuan dan peta wilayah kelola lahan.

Kegiatan kelembagaan yang pernah dilaksanakan, antara lain pelatihan pengelolaan organisasi dan keuangan, pertemuan rutin pengurus Gapoktan Wira Karya Sejahtera, dan pertemuan dengan stakeholder. Kegiatan pertemuan rutin pengurus gapoktan sudah sesuai dengan AD/ART Pasal 13 Ayat 1 yaitu: "rapat pengurus diselenggarakan sekurangkurangnya sekali dalam tiga bulan dan setiap waktu bila dianggap perlu oleh ketua". Setiap kegiatan diikuti pengurus KTH dan 2-3 anggota tani sebagai perwakilan. Pada tingkat KTH, kegiatan pertemuan rutin dalam jangka waktu tertentu masih jarang dilakukan, padahal kegiatan ini diadakan dengan tujuan meningkatkan struktur kelembagaan dan untuk meminimalisir terjadinya pelanggaran pemanfaatan kawasan. Sejalan dengan yang dijelaskan Laksemi et al. (2019) jika struktur kelembagaan tidak solid mengakibatkan maraknya pelanggaran di kawasan hutan.

Gapoktan menerapkan larangan dan sanksi yang disahkan dalam aturan main gapoktan berupa Surat Peringatan (SP) I, II dan III. SP ini berlaku untuk seluruh anggota gapoktan. Jika telah melampaui batas tersebut, maka akan dikeluarkan dari keanggotaan gapoktan. Jika ada yang merusak lahan HKm secara disengaja dari pihak luar, maka pengurus dan anggota gapoktan akan melaporkan ke polisi hutan dibawah naungan KPH Pematang Neba untuk diproses. Setiap anggota tani wajib mematuhi aturan main yang telah dibuat dan disepakati. Sejalan dengan Maryudi (2016) bahwa kelembagan harus diterjemahkan dalam aturan main yang disepakati sebagai sesuatu yang harus diikuti dan dipatuhi (memiliki kekuatan sanksi) dengan tujuan terciptanya keteraturan dan kepastian interaksi sosial.

\section{Kelola Kawasan}

Setiap anggota tani yang tergabung dalam gapoktan wajib menanam tanaman tajuk tinggi pada lahan garap mereka. Hal ini sudah sesuai dengan AD/ART Gapoktan Wira 
Karya Sejahtera pada Pasal 2 Ayat 9 yaitu: "setiap anggota kelompok tani wajib menanam tanaman tajuk tinggi, sedang dan rendah". Tanaman kopi digunakan sebagai komoditi utama di lahan HKm ini. Tanaman yang baik untuk ditanam diantara tanaman kopi, antara lain lamtoro, gamal, sengon, suren, mahoni, manga, nangka, jeruk, cengkeh, terong belanda (Hulupi \& Martini, 2013). Tanaman yang memiliki jarak tanam terlalu sempit akan membuat pertumbuhan tidak optimal (Mulyana et al., 2017), sehingga pemilihan jenis-jenis tanaman pohon lain perlu dipertimbangkan besaran dan kerapatan tajuknya agar tanaman kopi tidak terganggu (Ruchyansyah et al., 2018).

Pemahaman batas-batas wilayah kelola lahan dalam batas kawasan $\mathrm{HKm}$ telah dipahami oleh pengurus dan juga anggota tani. Tata batas lahan garapan antar anggota tani menggunakan pohon andong (Cordyline fructicosa), sedangkan tata batas lahan antar KTH dibatasi oleh bentang alam, seperti aliran sungai, pematang dan juga tanaman pisang. Pihak yang bertanggungjawab terkait batas-batas pembagian wilayah adalah pengurus dan anggota gapoktan. Adanya batas wilayah tersebut membantu anggota tani dalam mengklaim pengelolaan sumberdaya hutan. Sejalan dengan Marasabessy (2017) bahwa adanya batas-batas tersebut membuat wilayahnya menjadi eksklusif, dalam arti bahwa pengelolaan sumberdaya alam dan lingkungan menjadi hak masyarakat yang mengklaimnya.

Hasil hutan yang dapat diperoleh yaitu kopi (Coffea sp.), pala (Myristica fragrans), durian (Durio zibethinus), jengkol (Archidendron pauciflorum), petai (Parkia speciosa), nangka (Artocarpus heterophyllus), aren (Arenga pinnata), kakao (Theobroma cacao), dan alpukat (Persea americana) serta tanaman pertanian yaitu pisang (Musa acuminata). Rempah-rempah yang dihasilkan, seperti lada (Piper nigrum), cengkeh (Syzygium aromaticum) dan kemiri (Aleurites moluccana). Sumberdaya hutan yang dapat diakses berupa sumber mata air dan tanah. Setiap anggota tani memiliki hak yang sama dalam memanfaatkan sumberdaya hutan.

HKm yang dikelola Gapoktan Wira Karya Sejahtera memiliki beberapa jenis jasa lingkungan, antara lain wisata Bukit Neba berupa landscape beauty, sumber mata air dan keanekaragaman hayati berupa fauna. Fauna yang masih ada di kawasan HKm yaitu beruang madu (Helarctos malayanus) dan ayam hutan (Gallus sp.). Pemanfaatan potensi jasa lingkungan sudah sesuai dalam SK Bupati Tanggamus Nomor B.466/34/II/2014 tentang IUPHKm atas nama Gapoktan Wira Karya Sejahtera Kecamatan Gisting Kabupaten Tanggamus putusan ke-4 nomor 1 poin $b$ tentang hak dan kewajiban yang berbunyi: "melakukan kegiatan pemanfaatan jasa lingkungan".

\section{Kelola Usaha}

Hasil hutan non kayu yang menjadi komoditi utama adalah kopi. Kopi yang telah dipanen biasanya akan dijemur lalu dijual dengan harga kisaran Rp 17000-Rp 20000. Anggota tani melakukan pemeliharaan tanaman kopi mulai dari melakukan pemangkasan, pengendalian gulma, hama serta penyakit. Sejalan dengan Winarni et al. (2016) bahwa kegiatan pemeliharaan kopi yang baik meliputi pemangksaan, pengendalian gulma, pengendalian hama dan penyakit, serta pemupukan.

Berdasarkan Rencana Umum Gapoktan tahun 2015, usaha tani mulai direncanakan pada tahun 2016 untuk membantu memasarkan hasil hutan anggota tani. Usaha tani yang ada di wilayah Gapoktan Wira Karya Sejahtera dibagi menjadi dua, yaitu usaha individu dan usaha gapoktan. Usaha individu yang dijalankan yaitu penjualan kopi bubuk, bibit pertanian, pupuk kompos dan manisan pala. Usaha manisan pala merupakan hasil hutan non kayu yang cukup terkenal di Dusun Way Tebu. Sistem pejualan diarahkan langsung ke kelompok wanita tani dengan melakukan sistem pre-order. Usaha gapoktan yang dijalankan adalah usaha jual kopi bubuk dan bibit pertanian. Kelompok usaha ini dinaungi langsung oleh gapoktan. Usaha tani terkait penjualan kopi bubuk sendiri sudah melakukan kerjasama dengan HKm Mart Kecamatan Gisting dengan perjanjian berupa MoU. Kopi 
bubuk yang dijual masih menggunakan label HKm Mart pada kemasan. Kelompok usaha tani gapoktan saat ini hanya sebagai penyedia bahan baku kopi bubuk.

Gapoktan memiliki koperasi gapoktan dengan nama Koperasi Wira Karya Raharja. Koperasi ini mulai dibentuk pada bulan Oktober 2016 dan mendapat bantuan dari Dinas Koperasi dan Perdagangan Kabupaten Tanggamus dalam pembentukan koperasi primer. Pengelolaan koperasi dinaungi langsung oleh pengurus gapoktan yang masih tergolong aktif sebagai anggota tani. Namun, koperasi ini tidak berjalan dengan baik karena kurangnya perencanaan dalam pengelolaan koperasi. Kurangnya pengetahuan pengelolaan koperasi juga yang membuat kinerja koperasi tidak berjalan maksimal. Menurut Maramba (2018), beberapa orang sulit melaksanakan adopsi dan inovasi hasil hutan karena memiliki pendidikan rendah sehingga sulit untuk menangkap dan mencoba hal-hal yang baru.

\section{KESIMPULAN DAN SARAN}

Kelembagaan Gapoktan Wira Karya Sejahtera berperan dalam mengatur pengelolaan hutan kemasyarakatan agar lestari dan berkelanjutan. Secara kelembagaan gapoktan ini memiliki administrasi kelompok yang lengkap dan aturan main secara tertulis serta rencana kegiatan jangka panjang untuk mengidealkan pengelolaan hutan kemasyarakatan. Pada pengelolaan kawasan $\mathrm{HKm}$ menunjukkan bahwa anggota tani menggarap lahan dengan pola agroforestri yang didominasi tanaman MPTS agar dapat memperoleh hasil hutan lebih optimal. Pemasaran hasil hutan dilakukan secara individu maupun bersama gapoktan melalui kerjasama dengan dua institusi dalam memasarkan hasil hutan. Gapoktan memiliki usaha koperasi, namun belum ada perkembangan usaha tani selama dua tahun terakhir. Perlu adanya pengembangan kerjasama, jaringan kerja dan kemitraan dengan pelaku usaha untuk memaksimalkan pemasaran hasil hutan. Pemerintah dan dinas terkait perlu mengadakan penyuluhan terkait pengetahuan terhadap pengelolaan usaha tani agar anggota tani dapat memanfaatkan lahan dan memasarkan hasil hutan lebih maksimal.

\section{DAFTAR PUSTAKA}

Aminah, L. N. (2018). Analisis kelembagaan gapoktan di Kesatuan Pengelolaan Hutan IX Kota Agung Utara Kabupaten Tanggamus Provinsi Lampung. Thesis. Lampung: Universitas Lampung. $86 \mathrm{hlm}$.

Baral, S. (2018). Attempts of recentralization of Nepal's Community Forestry. Journal of Institute of Forestry, 15, 97-115.

Caballero, G. (2014). Community-based forest management institutions in the Galician communal forests: A new institutional approach. Forest Policy and Economics, 50, 347-356. doi: 10.1016/j.forpol.2014.07.013.

Febryano, I. G. (2014). Politik Ekologi Pengelolaan Mangrove di Kabupaten Pesawaran Provinsi Lampung. Disertasi. Bogor: Institut Pertanian Bogor. $113 \mathrm{hlm}$.

Febryano, I. G., Sinurat, J. \& Salampessy, M. L. (2017). Social relation between businessman and community in management of intensive shrimp pond. Earth and Environmental Science, 55(1), 1-7. doi: 10.1088/1755-1315/55 /1/012042.

Gibran, I.A., H. Augustrie, N. \& Rahmaniyah, S. (2018). Peran pemimpin gabungan kelompok tani di Kelurahan Karangrejo Kecamatan Sumbersari Kabupaten Jember. Jurnal Sosial Ekonomi Pertanian, 12(1), 39-53. doi: 10.24843/SOCA.2018.v12.i01.p03.

Hulupi, R. \& Martini, E. (2013). Pedoman budi daya dan pemeliharaan tanaman kopi di kebun campur. Bogor, Indonesia: World Agroforestry Centre (ICRAF) Southeast Asia Regional Program. 72 hlm. 
Kaskoyo, H., Mohammed, A.J. \& Inoue, M. (2014). Present state of community forestry: Program in a protection forest and it's callenges, case study in Lampung Province. Journal of Forest Science, 30(1), 15-29. doi: 10.7747/ifs .2014.30.1.15.

Kaskoyo, H., Mohammed, A. J. \& Inoue, M. (2017). Impact of community forest program in protection forest on livelihood outcomes: A case study of Lampung Province, Indonesia. Journal of Sustainable Forestry, 36(3), 250-263. doi: 10.1080/10549811.2017.1296774.

Laksemi, N. P. S. T., Sulistyawati, E. \& Mulyaningrum. (2019). Perhutanan sosial berkelanjutan di Provinsi Bali (Studi kasus di Hutan Desa Wanagiri). Jurnal Sylva Lestari, 7(2), 150-163. doi: 10.23960/jsl27150-163.

Lewis, R. A. \& Davis, S. R. (2015). Forest certification, institutional capacity, and learning: An analysis of the impacts of the Malaysian timber certification scheme. Forest Policy and Economics, 52, 18-26. doi: 10.1016/j.forpol.20 14.12.011.

Maramba, U. (2018). Pengaruh karakteristik terhadap pendapatan petani jagung di Kabupaten Sumba Timur (Studi Kasus: Desa Kiritana, Kecamatan Kambera, Kabupaten Sumba Timur). Jurnal Ekonomi Pertanian dan Agribisnis, 2(2), 94101.

Marasabessy, H. (2017). Kearifan lokal dalam pengelolaan hutan (Studi kasus kelembagaan sasi hutan di Desa Kailolo Kecamatan Pulau Haruku Kabupaten Maluku Tengah). Jurnal Hutan Pulau-Pulau Kecil, 2(1), 49-69. doi: 10.30598/jhppk.2018.2.1.49.

Maryudi, A. (2016). Arahan tata hubungan kelembagaan Kesatuan Pengelolaan Hutan (KPH) di Indonesia. Jurnal IImu Kehutanan, 10(1), 57-64.

Mulyana, L., Febryano, I. G., Safe'i, R. \& Banuwa, I. S. (2017). Performa Pengelolaan agroforestri di Wilayah Kesatuan Pengelolaan Hutan Lindung Rajabasa. Jurnal Hutan Tropis, 5(2), 127-133.

Nasichah, Z., Harianto, S. P. \& Winarno, G. D. (2018). Mitigasi gangguan simpai (Presbitys melalophos) pada lahan agroforestri di Hutan Lindung Register 25 Pematang Tanggang, Kelumbayan, Tanggamus. Jurnal Sylva Lestari, 6(2), 7-15.

Persson, J. \& Prowse, M. (2017). Collective action on forest governance: An institutional analysis of the Cambodian community forest system. Forest Policy and Economics, 83, 70-79. doi: 10.1016/.j.forpol.2017.06.008.

Porro, R., Porro, N. S. M., Menezes, M. C. \& Bartholdson, O. (2015). Collective action and forest management: Institutional challenges for the environmental agrarian reform in Anapu, Brazilian Amazon. International Forestry Review, 17(1), $20-36$.

Rajagukguk, C. P., Febryano, I. G. \& Herwanti, S. (2018). Perubahan komposisi jenis tanaman dan pola tanam pada pengelolaan agroforestri damar. Jurnal Sylva Lestari, 6(3), 18-27. doi: 10.23960/jsl3618-27.

Ruchyansyah, Y., Wulandari, C. \& Riniarti, M. (2018). Pengaruh pola budidaya pada hutan kemasyarakatan di areal kelola KPH VIII Batutegi terhadap pendapatan petani dan kesuburan tanah. Jurnal Sylva Lestari, 6(1), 100-106. doi: 10.23960/jsl16100-106.

Safe'i, R., Febryano, I. G. \& Aminah, L. (2018). Pengaruh keberadaan gabungan kelompok tani terhadap pendapatan petani dan perubahan tutupan lahan di hutan kemasyarakatan. Jurnal Sosiohumaniora, 20(2), 109-114. doi: 10.24 198/sosiohumanio ra.v20i2.14349.

Salampessy, M. L., Bone, I. \& Febryano, I. G. (2012). Performansi dusung pala sebagai salah satu agroforestri tradisional di Maluku. Jurnal Tengkawang, 2(2), 55-65.

Schmid, A. A. (2004). Conflictand Cooperation Institutional and Behavioral Economics. Inggris: Blackwell Publishing. $139 \mathrm{hlm}$. 
Stoen, M. A. (2018). Social forestry movements and science-policy networks: The politics of the forestry incentives program in Guatemala. Geoforum, 90, 20-26. doi: 10.1016/i.geoforum.2018.01.014.

Sugiyono. (2017). Metode Penelitian Kuantitatif, Kualitatif, dan R\&D. Bandung: Alfabeta CV. $334 \mathrm{hlm}$.

Sya'rani, R., Awang, S. A., Supriyatno,N. \& Purwanto, R. H. (2017). Universum kelembagaan Kesatuan Pengelolaa Hutan Produksi (KPHP) Model Kabupaten Banjar Provinsi Kalimantan Selatan. Jurnal Hutan Pulau-Pulau Kecil, 1(2), 143150. doi: $10.30598 /$ ihppk.2016.1.2.143.

Vega, D. C. (2019). Community-based forestry and community forestry enterprises in Quintana Roo, Mexico and Petén, Guatemala: How have policies, history, and culture shaped their trajectories?. Journal of Sustainable Forestry, 38(7), 651669. doi: $10.1080 / 10549811.2019 .1598875$.

Winarni, S., Yuwono, S. B. \& Herwanti, S. (2016). Struktur pendapatan, tingkat kesejahteraan dan faktor produksi agroforestri kopi pada Kesatuan Pengelolaan Hutan Lindung Batutegi (Studi di Gabungan Kelompok Tani Karya Tani Mandiri). Jurnal Sylva Lestari, 4(1), 1-10. doi: 10.23960/jsl141-10. 